\title{
CORRIGENDUM
}

\section{Solution-deposited sodium beta-alumina gate dielectrics for low-voltage and transparent field-effect transistors}

Bhola N. Pal, Bal Mukund Dhar, Kevin C. See and Howard E. Katz

Nature Materials 8, 898-903 (2009); published online: 18 October 2009; corrected after print: 3 February 2010.

In Fig. 2b on page 900 of the above Article, the vertical axis labelling was incorrect and should have appeared as shown on the right. Also, in the Methods section, "0.041 mg" should have been "0.041 g".

These errors have been corrected in the HTML and PDF versions of this Article.

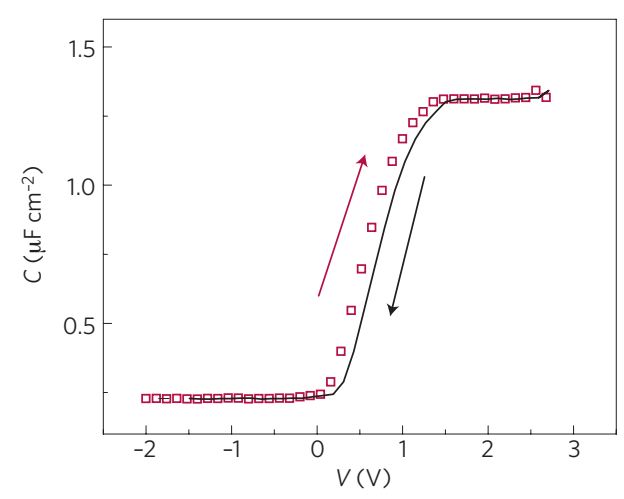

